\title{
Problems and Countermeasures of Local Emergency Management in China
}

\author{
Shiqi Shao \\ School of Public Management/Emergency Management, Research Center of Emergency Management, Jinan University, \\ Guangzhou, China \\ Email: sunshine_0820@qq.com
}

How to cite this paper: Shao, S.Q. (2017) Problems and Countermeasures of Local Emergency Management in China. Open Journal of Social Sciences, 5, 64-79. https://doi.org/10.4236/jss.2017.55006

Received: March 28, 2017

Accepted: May 9, 2017

Published: May 12, 2017

Copyright $\odot 2017$ by author and Scientific Research Publishing Inc. This work is licensed under the Creative Commons Attribution International License (CC BY 4.0).

http://creativecommons.org/licenses/by/4.0/

\section{Open Access}

\begin{abstract}
Local government is the primary perception and responder in emergency management, and their ability to deal with emergencies and the response to the level of good or bad, is directly related to the organization that can effectively reduce the economic losses caused by the incident and casualties. Therefore, it is very important to find out the problems in the emergency management of the local and take corresponding countermeasures to improve the emergency management level of the local government. Based on the theoretical framework of cross-organizational cooperation and the empirical research, this paper describes the inter-organizational cooperation situation of local government emergency management and finds out the key factors that affect the cross-organization cooperation of local government. Finally, some suggestions are put forward for the emergency management of local government in China.
\end{abstract}

\section{Keywords}

Emergency Management, Cross-Organizational Cooperation, Local Government

\section{Introduction}

With the development of society and economy, the impact of disasters is increasing, and the number of disaster factors continues to increase, which has made the government more difficult to manage the crisis. In the face of complexity, diversity, dynamic characteristics, the cross-organizational cooperation model of "government-led, social participation" was established.

The basic organization of emergency management is the local government, which can understand the detailed geographical environment and human cha- 
racteristics in its region. At the same time, the local government can combine the characteristics of the region to effectively deal with emergencies. More importantly, the State Council put forward the comprehensive strengthening views of emergency management work, which required improving the emergency management system of classification and combination. However, it is not a single sector that can be achieved the emergency responses, especially when faced with the situation of cooperation. At that time, all kinds of emergency resources distributed in different units, and existed the characteristics of a high degree of fragmentation, which increased the difficulties in common decision-making and the emergency resources and information sharing. Therefore, it is essential for local government and its directly under-department, district units, enterprises and social organizations to cooperate with each other to cope with the disaster. And if necessary, the request of support from higher levels of government and other local governments must also take into consideration. Especially when faced with the central authority of the leading position of China's emergency management system, local government between the horizontal cooperation is relatively weak. Thus, it is essential to strengthen horizontal cooperation between local governments for integrating emergency resources, including rights, information, contingency, finance and expertise that are scattered across sectors.

This paper constructs a theoretical framework to analyze the inter-organizational cooperation of local government emergency management by using the theory of inter-organizational cooperation, and analyzes the current situation of emergency management cooperation among several local governments in China from five dimensions, and on this basis, this paper puts forward the measures to enhance the emergency management cooperation level of local government. The research of this paper can provide an effective means to enhance the level of emergency management cooperation of the local government and maximize the emergency management ability of the local government.

\section{Local Government Emergency Management Theory of Cross-Organizational Cooperation Framework}

Cooperation is an autonomous and semi-autonomous entity through formal and informal consultations to interact, to develop management relations between the rules and structure of partners, but also a shared model and mutual benefit of the interaction [1]. Local government cross-organizational cooperation of emergency management refers to the face of emergencies emergency management of this complex social problem, the need for emergency management responsibilities of multiple units to cooperate with each other to complete the maximum use of resources, reduce casualties and property damage caused by emergencies.

\subsection{Construction of the Framework of Foreign Cross-Organizational Cooperation}

Scholars have a certain similarity to the construction of the framework of inter- 
organizational cooperation, which involves the initial conditions, processes, structure and cooperation results of inter-organizational cooperation. Bryson [2] and other scholars believe that cross-sectoral co-operation is a viable strategy in the face of complex social problems in the public sector. Cross-sectoral coordination consists of five parts: initial conditions, processes, structures and governance, the consequences and responsibilities of accidents and restrictions, and through the five main elements to build cross-sectoral coordination of the structural framework, from the architecture to cross-sectoral governance extension of the development of the recommendations, so that people have a more image of the cross-sector management and specific understanding. Ansell and Gash [3], focus on the elements of the cooperation process: face-to-face communication, confidence-building, process agreement establishment and mutual understanding, and the limitation of cooperation process, the uncontrollable factors include: time, trust, independence. Provan and Kenis [4] mainly study the governance structure type, the key constraint condition and the opposition factor based on the network theory, take the path of the evolution of the governance system over time into account. Governance structure type has self-organization structure, has the structure of lead organization, network supervision organization. Constraints include: degree of trust, number of participants, goal consistency, network management requirements and competency levels. Through the efficiency and quality, internal legitimacy and external legitimacy, flexibility and stability of the description to reflect the opposing factors. On this basis, the influence of time factor on the evolution of governance system is considered. Emerson [5] regards cross-organizational cooperation as overall view of the system, and thought that cross-organizational cooperation theory framework includes drivers, cooperative governance system, cooperation mechanisms, mobility, impact and adaptability. Koschmann, Kuhn, and Pfarrer [6] proposed the importance of communication for cross-organizational cooperation, while emphasizing the role of authoritative texts (including: cooperation norms, legal provisions, task descriptions, organizational responsibilities, etc.) in promoting intercultural communication. Thus, they constructed a theoretical framework for the exchange of practice, authoritative text, and communication practices across cross-partner values.

\subsection{A Study on the Theoretical Framework of Cross-Organizational Cooperation in China}

Zhong Kaibin [7] use the interpretation framework of "information source - information channel" to prove that the clear source of information and open information channels are important for emergency decision-making. We must improve emergency decision-making ability and level of the multi-subject, multi-stage and multi-level from the information point of view, establish a multiagent coordination mechanism based on information, integrate different regions, different departments, different systems and different levels of emergency forces and resources. Pan Fei and other scholars [8] established a complete set of 
MCS determinants (control problems and abilities), control mechanism (formal control/informal control), performance consequences Research framework, which based on integrating transaction cost economics theory, organizational contingency theory and resource view, and at the same time, supplement the concept of resources as a theoretical basis, which depend on comprehensive consideration of demand and supply of these two factors, integrated the study of cross-organizational frameworks. Ren Xiaochun [9] summed up the cooperation between the various co-operation with the matching, consistency, orderly, dynamic and effective features, proposed cooperative governance is an effective way to achieve from governance to good governance. Through the theoretical framework of public service network governance in China, Zhou Yue [10] put forward the common governance model, that is, the mode of cooperation between organizations, refers to the government, enterprises, non-governmental organizations and users of equal cooperation between the model, to participate in the process of public service supply, The core condition is the trust mechanism, the important condition is the responsibility mechanism, the guarantee condition is the supervisory mechanism, therefore, it is very important to establish the cross-border cooperation to provide the public service.

\subsection{Local Government Emergency Management Theory of Cross-Organizational Cooperation Framework}

The goal that local government cross-organizational cooperation of emergency management is to establish government leadership, social participation, the combination of emergency linkage mechanism to promote highly shared and efficient use of information, knowledge and resources in the emergency management, and to achieve the maximum intervention and suppression of emergencies, its essence is to achieve the emergency goal, and build an emergency service delivery path. Most experts and scholars believe that the way of collaboration can provide a more effective solution for disaster response [11]. Governments and departments at all levels must identify strategies within the "acceptable risk" [12] and quickly form an emergency response system [13] [14]. In order to have the ability to share information, resources, activities, and to achieve the goal that cannot be completed in a single department, the local government suggest that use multi-organization cooperation to deal with emergencies. Therefore, the local level of emergency response needs to be strengthened [15], by reducing the independence of a single department, to achieve emergency management work between the joint decision-making and implementation. At the same time, the partnership is based on the understanding that resource cooperation plays an important role in achieving a successful response to the crisis [16], raising the level of local government emergency management through inter-organizational resource sharing. Chen and Graddy [17] (2005) argue that trust between members of the organization can create a sense of goodwill between each other, which helps to coordinate the links and behaviors between organizations and promote the confidence of members in the outcome of the cooperation. Therefore, en- 
hancing the level of trust between organizations has an important impact on improving the results of cooperation between the various departments at the local level.

\section{Investigation and Analysis of Emergency Management Cooperation in Local Government}

\subsection{Five Dimensions of Emergency Management Cooperation in Local Government}

The essence of cooperation in local government emergency management is to coordinate the emergency services rapidly, protect the affected people's lives and property to the utmost, reduce environmental pollution, maintain social policy order.

\section{Dimension 1: Joint decision making}

1. Partner organizations take your organization's opinions seriously when decisions are made about the collaboration.

2. Your organization brainstorms with partner organizations to develop solutions to mission-related problems facing the collaboration.

\section{Dimension 2: Joint implementation}

1. You, as a representative of your organization in the collaboration, understand your organization's roles and responsibilities as a member of the collaboration.

2. Partner organization meetings accomplish what is necessary for the collaboration to function well.

3. Partner organizations (including your organization) agree about the goals of the collaboration.

4. Your organization's tasks in the collaboration are well coordinated with those of partner organizations.

\section{Dimension 3: Reduce autonomy}

1. The collaboration hinders your organization from meeting its own organizational mission.

2. Your organization's independence is affected by having to work with partner organizations on activities related to the collaboration.

3. You, as a representative of your organization, feel pulled between trying to meet both your organization's and the collaboration's expectations.

\section{Dimension 4: Resource sharing}

1. Partner organizations (including your organization) have combined and used each other's resources so all partners benefit from collaborating.

2. Your organization shares information with partner organizations that will strengthen their operations and programs?

3. You feel what your organization brings to the collaboration is appreciated and respected by partner organizations.

4. Your organization achieves its own goals better working with partner organizations than working alone.

5. Partner organizations (including your organization) work through differ- 
ences to arrive at win-win solutions?

\section{Dimension 5: trust level}

1. The people who represent partner organizations in the collaboration are trustworthy.

2. My organization can count on each partner organization to meet its obligations to the collaboration.

3. Your organization feels it worthwhile to stay and work with partner organizations rather than leave the collaboration.

\subsection{Data Sources}

In this paper, we use the Likert 7-point scale questionnaire to collect data, and see Table 1 for specific information. The questionnaire was a combination of Thomson and Perry [18] on the five dimensions of the cooperation process on the impact of the results of the scale and the actual work of emergency management. In order to investigate the level of inter-organizational cooperation among the local governments, this paper chooses the member of the Emergency Management Committee of Shenzhen City, Guangdong Province, the Guigang Emergency Management Committee of Guigang City, Guangxi Province, and the member of the Emergency Management Committee of Qingdao City, Shandong Province as the research object. A total of 160 questionnaires were collected from 17 dimensions of emergency management cooperation, and 148 valid questionnaires were collected. The effective recovery rate was $92.5 \%$.

\subsection{Investigation and Analysis Based on Three Local Governments}

\subsubsection{Analysis of Demographic Characteristics}

The demographic characteristics of the survey sample are shown in Table 2. As can be seen from Table 2, most of the investigated government staff are in the deputy and the level of the Division, accounting for nearly $50 \%$, the proportion of position of the job in the 1 year to 5 years is $61.5 \%$, engaged in emergency management work in the time of 1 year to 3 years, accounting for $68.9 \%$ of the total proportion. The above description explained that most of the emergency mangers are the relevant departments of the leadership who directly engaged in this work, but the time is not very long.

\subsubsection{Analysis of Reliability and Validity}

\section{- Analysis Cronbach's alpha reliability}

The data of the valid questionnaire were all imported into SPSS18.0 software, and the reliability of the questionnaire survey was calculated. The Cronbach's Alpha reliability analysis table was obtained as shown in Table 3.

It can be seen from Table 3 that the value of Cronbach's Alpha is 0.919 and the value of Cronbach's Alpha based on the normalized item is 0.892 , which is greater than 0.8. At the same time, through the analysis results (Table 4), the Cronbach alpha coefficient Cronbach's Alpha, CA) between 0.824 and 0.940, the reliability of the total scale reached 0.919 , indicating that the questionnaire has a 
Table 1. The information of the questionnaire.

\begin{tabular}{|c|c|c|c|c|c|c|c|}
\hline \multirow{2}{*}{$\begin{array}{l}\text { Survey Item } \\
\text { 1. Partner organizations take your organization's opinions } \\
\text { seriously when decisions are made about the collaboration. }\end{array}$} & \multicolumn{3}{|c|}{$\begin{array}{l}\text { Strongly } \\
\text { Disagree }\end{array}$} & \multicolumn{4}{|c|}{ Strongly agree } \\
\hline & 1 & 2 & 3 & 4 & 5 & 6 & 7 \\
\hline $\begin{array}{l}\text { 2. Your organization brainstorms with partner } \\
\text { organizations to develop solutions to mission-related } \\
\text { problems facing the collaboration. }\end{array}$ & 1 & 2 & 3 & 4 & 5 & 6 & 7 \\
\hline $\begin{array}{l}\text { 3. You, as a representative of your organization in the col- } \\
\text { laboration, understand your organization's roles and re- } \\
\text { sponsibilities as a member of the collaboration. }\end{array}$ & 1 & 2 & 3 & 4 & 5 & 6 & 7 \\
\hline $\begin{array}{l}\text { 4. Partner organization meetings accomplish what is } \\
\text { necessary for the collaboration to function well. }\end{array}$ & 1 & 2 & 3 & 4 & 5 & 6 & 7 \\
\hline $\begin{array}{l}\text { 5. Partner organizations (including your organization) } \\
\text { agree about the goals of the collaboration. }\end{array}$ & 1 & 2 & 3 & 4 & 5 & 6 & 7 \\
\hline $\begin{array}{l}\text { 6. Your organization's tasks in the collaboration are } \\
\text { well coordinated with those of partner organizations. }\end{array}$ & 1 & 2 & 3 & 4 & 5 & 6 & 7 \\
\hline $\begin{array}{l}\text { 7. The collaboration hinders your organization from } \\
\text { meeting its own organizational mission. }\end{array}$ & 1 & 2 & 3 & 4 & 5 & 6 & 7 \\
\hline $\begin{array}{l}\text { 8. Your organization's independence is affected by } \\
\text { having to work with partner organizations on } \\
\text { activities related to the collaboration. }\end{array}$ & 1 & 2 & 3 & 4 & 5 & 6 & 7 \\
\hline $\begin{array}{l}\text { 9. You, as a representative of your organization, feel } \\
\text { pulled between trying to meet both your organization's } \\
\text { and the collaboration's expectations. }\end{array}$ & 1 & 2 & 3 & 4 & 5 & 6 & 7 \\
\hline $\begin{array}{l}\text { 10. Partner organizations (including your organization) } \\
\text { have combined and used each other's resources } \\
\text { so all partners benefit from collaborating. }\end{array}$ & 1 & 2 & 3 & 4 & 5 & 6 & 7 \\
\hline $\begin{array}{l}\text { 11. Your organization shares information with } \\
\text { partner organizations that will strengthen their } \\
\text { operations and programs. }\end{array}$ & 1 & 2 & 3 & 4 & 5 & 6 & 7 \\
\hline $\begin{array}{l}\text { 12. You feel what your organization brings to the } \\
\text { collaboration is appreciated and respected } \\
\text { by partner organizations. }\end{array}$ & 1 & 2 & 3 & 4 & 5 & 6 & 7 \\
\hline $\begin{array}{l}\text { 13. Your organization achieves its own goals better working } \\
\text { with partner organizations than working alone. }\end{array}$ & 1 & 2 & 3 & 4 & 5 & 6 & 7 \\
\hline $\begin{array}{l}\text { 14. Partner organizations (including your organization) } \\
\text { work through differences to arrive at win-win solutions. }\end{array}$ & 1 & 2 & 3 & 4 & 5 & 6 & 7 \\
\hline $\begin{array}{l}\text { 15. The people who represent partner } \\
\text { organizations in the collaboration are trustworthy. }\end{array}$ & 1 & 2 & 3 & 4 & 5 & 6 & 7 \\
\hline $\begin{array}{l}\text { 16. My organization can count on each partner } \\
\text { organization to meet its obligations to the collaboration. }\end{array}$ & 1 & 2 & 3 & 4 & 5 & 6 & 7 \\
\hline $\begin{array}{l}\text { 17. Your organization feels it worthwhile to } \\
\text { stay and work with partner organizations } \\
\text { rather than leave the collaboration. }\end{array}$ & 1 & 2 & 3 & 4 & 5 & 6 & 7 \\
\hline
\end{tabular}

Strongly Disagree $=1$ Disagree $=2$ Less Disagree $=3$ Neither agree nor disagree $=4$ More agree $=5$ Agree $=$ 6 Strongly agree $=7$.

high degree of reliability, and the items have a good consistency.

\section{- Analysis of KMO and Bartlett}

Validity that is effective, is a measure of whether the comprehensive evalua- 
Table 2. The basic situation of the respondents.

\begin{tabular}{|c|c|c|c|c|c|c|c|c|c|}
\hline Duties & $\begin{array}{l}\text { Director } \\
\text { level }\end{array}$ & $\begin{array}{l}\text { Deputy } \\
\text { director }\end{array}$ & $\begin{array}{l}\text { Section } \\
\text { level }\end{array}$ & $\begin{array}{c}\text { Assistant } \\
\text { level }\end{array}$ & $\begin{array}{l}\text { Chief } \\
\text { Section }\end{array}$ & $\begin{array}{l}\text { Deputy Chief } \\
\text { section level }\end{array}$ & Staff & $\begin{array}{c}\text { Employee } \\
\text { Member }\end{array}$ & Other \\
\hline Frequency & 0 & 0 & 11 & 34 & 38 & 29 & 24 & 5 & 7 \\
\hline $\begin{array}{l}\text { Proportion } \\
\quad(\%)\end{array}$ & 0 & 0 & 7.4 & 23.0 & 25.7 & 19.6 & 16.2 & 3.4 & 4.7 \\
\hline \multicolumn{3}{|c|}{ Working Time (year) } & $1-5$ & $6-10$ & $11-15$ & $16-20$ & $\geqq 21$ & & \\
\hline \multicolumn{3}{|l|}{ Frequency } & 91 & 36 & 7 & 7 & 7 & & \\
\hline \multicolumn{3}{|c|}{$\begin{array}{l}\text { Proportion } \\
\qquad(\%)\end{array}$} & 61.5 & 24.3 & 4.7 & 4.7 & 4.7 & & \\
\hline \multicolumn{3}{|c|}{$\begin{array}{l}\text { emergencymanagement } \\
\text { work time (year) }\end{array}$} & $1-3$ & $4-6$ & $7-9$ & $10-12$ & $\geqq 12$ & & \\
\hline Frequency & & & 102 & 24 & 11 & 6 & 5 & & \\
\hline $\begin{array}{l}\text { Proportion } \\
\quad(\%)\end{array}$ & & & 68.9 & 16.2 & 7.4 & 4.1 & 3.4 & & \\
\hline
\end{tabular}

Table 3. Reliability analysis of the questionnaire.

\begin{tabular}{ccc}
\hline Cronbach's Alpha & Cronbach's Alpha based on standardized items & Items \\
\hline 0.919 & 0.892 & 20 \\
\hline
\end{tabular}

Table 4. The reliability factor of each dimension of the questionnaire.

\begin{tabular}{ccc}
\hline Potential variable & Observation variables & Alpha coefficient \\
\hline Joint decision making & $\mathrm{x}_{1}-\mathrm{x}_{2}$ & 0.824 \\
Joint implementation & $\mathrm{x}_{3}-\mathrm{x}_{6}$ & 0.863 \\
Reduce autonomy & $\mathrm{x}_{7}-\mathrm{x}_{9}$ & 0.818 \\
Resource sharing & $\mathrm{x}_{10}-\mathrm{x}_{14}$ & 0.940 \\
Trust level & $\mathrm{x}_{15}-\mathrm{x}_{1}$ & 0.921 \\
Cooperation results & $\mathrm{y}_{1}-\mathrm{y}_{3}$ & 0.890 \\
Total scale & $\mathrm{y}_{1}-\mathrm{y}_{3}, \mathrm{x}_{1}-\mathrm{x}$ & 0.919 \\
\hline
\end{tabular}

tion system can accurately reflect the purpose and requirements of evaluation, refers to the degree to which the measurement tool can measure the correctness of the feature to be measured. The higher the validity, the more the measurement results show the characteristics of the measurement, and vice versa. Among them, the structural validity refers to the measurement results reflected in a structure and the correspondence between the degree of measurement, structural validity analysis method used is factor analysis. In order to investigate the adequacy of the sample and the suitability of the principal component analysis, the data were processed using the KMO and Bartlett tests. The results are shown in Table 5.

In general, the closer the sample size (KMO) is closer to 1, the larger the sample size is, and the KMO value is 0.915 , indicating that the sample is well. The Bartlett test was used to test the correlation between the variables. If the significance level of the Bartlett test was 0.05, the partial correlation between the va- 
Table 5. KMO and Bartlett test results for the questionnaire.

\begin{tabular}{ccc}
\hline Sampling enough KMO metrics & & 0.915 \\
\hline Bartlett's Spherical Test & Approximate card side & 2502.228 \\
& Df & 190 \\
& Sig. & 0.000 \\
\hline
\end{tabular}

riables was considered small and suitable for factor analysis. The results of this measurement show that the $\mathrm{P}$ value is $0.000(\mathrm{P}<0.001)$, and the Bartlett's spherical test shows that the correlation between the samples is high, so the sample data are suitable for principal component factor analysis.

\section{- Analysis on the Current Situation of Cross-organizational Cooperation in Emergency Management}

The data was put into SPSS, and compared the statistical results of the specific items in the five dimensions of the process of cross-organization cooperation, as shown in Figure 1. It can be seen from Figure 1 and Table 6 that the mean of the "common decision-making plan" of 5.9 is greater than the average of 5.53 in the "Suggested Adoption" in the joint development of dimension 1 (D1), indicating that the joint decision-making scheme has higher recognition of the impact of joint development. In the joint implementation of dimension 2 (D2), the mean of "understanding the role of the unit's cooperation" is 6.26 , and the mean of the "recognized target" is 6.07 , which is relatively large, indicating the influence of the two items on D2 higher. While dimension 3 (D3) is the opposite measure, the lower the value, the more willing to give up autonomy and carry out cooperation. Among them, the "independent mission and the expectations of cooperation between the contradictions" and "independence by the impact of cooperation" are well expressed to reduce the autonomy of this dimension, the average is 2.07. In the dimension 4 (D4) resource sharing, the average of the items is from large to small, followed by "cooperation is better than independent action" 5.90, "cooperation to achieve win-win" 5.78, "pay to enjoy and respect" 5.77, "emergency information" 5.75, "emergency resources" 5.69, indicating that most organizations believe that cooperation is beneficial to resource sharing. Finally, dimension 5 (D5) trust level, "the degree of recognition of common work" is conducive to improving the level of trust, the average value of the item is 5.93 . On the whole, the mean difference between the dimensions is small and both are at levels greater than 5 or less than 3 (reverse measurement), indicating that the organization for the process of cooperation in the joint development, joint implementation, reduce autonomy, resource sharing, trust level of recognition is not very different, but all agree with the attitude, can further strengthen the degree of cooperation between the inter-organizational, so as to improve the level of cooperation in emergency management.

\section{The Existence of the Problem}

Local government inter-organizational cooperation of emergency management involves emergency linkage mechanism construction, emergency management 


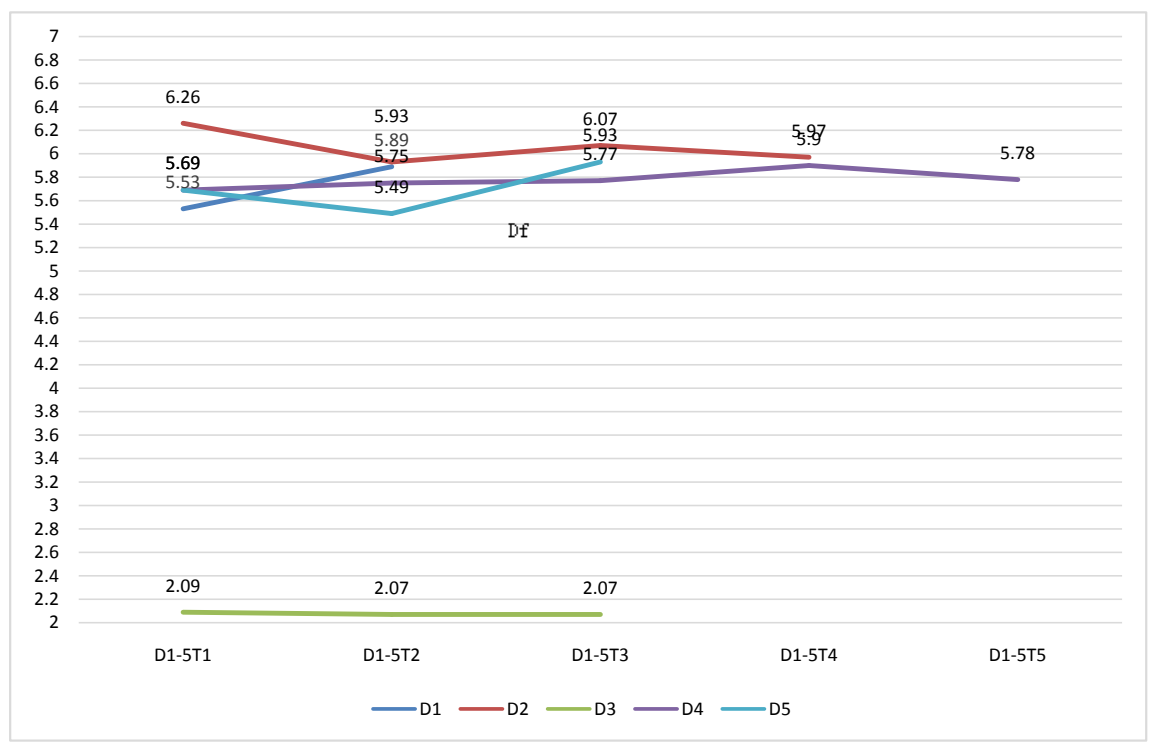

Figure 1. Analysis of the status quo of cross-organizational cooperation in emergency management.

Table 6. Summary of the dimensions of the process of cross-organizational cooperation in emergency management.

\begin{tabular}{lcccccc}
\hline & $\mathrm{D}_{1-5} \mathrm{~T}_{1}$ & $\mathrm{D}_{1-5} \mathrm{~T}_{2}$ & $\mathrm{D}_{1-5} \mathrm{~T}_{3}$ & $\mathrm{D}_{1-5} \mathrm{~T}_{4}$ & $\mathrm{D}_{1-5} \mathrm{~T}_{5}$ & Total scale \\
\hline D1: Joint decision making & 5.53 & 5.89 & & & & 5.71 \\
D2: Joint implementation & 6.26 & 5.93 & 6.07 & 5.97 & & 6.06 \\
D3: Reduce autonomy & 2.09 & 2.07 & 2.07 & & & 2.08 \\
D4: Trust level & 5.69 & 5.75 & 5.77 & 5.90 & 5.78 & 5.78 \\
D5: Cooperation results & 5.69 & 5.69 & 5.93 & & & 5.70 \\
\hline
\end{tabular}

responsibility system construction, and hinder the emergency management of cross-organizational cooperation factors and other aspects of research. At the same time, in order to further improve the local government cross-organizational cooperation process of emergency management to provide scientific guidance, this paper analyzed the existence obstacles in the local government emergency management linkage system between the different emergency management units of information and knowledge sharing, coordination of emergency management, emergency management responsibility to fulfill, as well as emergency targets to achieve the key factors and problems and causes.

\subsection{The Construction of Specialized Team of Emergency Management in local Government}

Through the survey found that personnel engaged in emergency management work mobility, especially the emergency management staff working period is not long, resulting in unexpected events, cannot be rich experience, professional quality and effective response to the crisis. The reason why the work of local government in emergency management is not high efficiency is that it lacks stability in emergency management team, and doesn't have the subjective initiative 
to carry out emergency work and other reasons.

\subsection{The Level of Joint Development between Government Departments Needs to Be Improved}

First of all, the coordination process of the functional teams of the local governments in the plan and the support units of the supporting units has not yet been established. The responsibilities between the lead unit and the support unit are not clear and will affect the cooperation between the lead unit and the support unit, resulting in the inability to effectively mobilize the enthusiasm of the units and provide specific emergency functions and services. Second, the function between different groups of the local government special emergency headquarters has a small difference, and similar functional groups between the members of the unit are different, which affect the local government emergency response unit to cooperate.

\subsection{Fragmentation of Inter-Organizational Relationships, Resulting in Unfavorable Cooperation between Inter-Organizational, Affecting the Level of Joint Implementation}

Fragmentation of inter-organizational relationships not only includes the relationship between local governments and central enterprises, as well as between military and armed police in emergency management. Second, it is obvious that the local government emergency committee member units exist the characteristics of segmentation. It should be improved in the communication, knowledge and emergency resources sharing between the district government, the street offices and the district departments with industry supervision responsibilities. At the same time, the management authority between the various departments of the local level is not affiliated with each other, and the financial support channels are different. In the emergency management work, there is overlap and cross between the contents of the work, affecting the cooperation of the units in the emergency work with the district government and the relevant departments.

\subsection{Local Government Inter-Organizational Cooperation of Emergency Management between the Level of Resource Sharing Is Not High}

During the work in the emergency management, there exist many problems, such as the vague boundary between the functions of the departments and the administrative power, the division of the departments, weak emergency coordination, and cannot to integrate the resource and take response rapidly. Different departments have different areas of resources, local government emergency committees and member units need to further strengthen the cooperation mechanisms of the emergency information and knowledge sharing, emergency resource optimization and utilization. There is a relatively small number of direct cooperation and contact between the various departments at the district level, and the lack of direct emergency management cooperation mechanism between 
the organizations greatly reduces the efficiency of information communication and knowledge sharing in emergency management work and hinders the improvement of emergency management performance level.

\subsection{Local Governments Are Not Well Established in Fostering Inter-Sectoral Trust Mechanisms}

Trust is the prerequisite for cooperation, the trust between the grassroots government departments is mainly reflected in the sharing of resources and information disclosure, information disclosure is not only the basic content of the government legal system construction, but also a very critical case, and our grassroots government has not yet established Improve the emergency management information disclosure system, hinder the improvement of emergency efficiency. At the same time, trust is the basis of joint development and implementation, and the units in the contingency planning, emergency resource management, public safety risk management, emergency response and other work still exist unclear responsibilities, departments tend to prevaricate between each other, which cannot have a very good recognition of partner for cooperative action. Thus, it has low trust.

\section{Suggestions}

On the basis of analyzing the problems and causes of the inter-organizational cooperation in the emergency management of the local government, the paper puts forward the measures to strengthen the cross-organization cooperation of the local government emergency management, and establish a platform for emergency management information disclosure, trying to mobilize the maximum public sector and social forces to participate in emergency management, to speed up the emergency information, knowledge and resources sharing, so as to obtain the greatest emergency management cooperation effect.

\subsection{Carry out the Training on Local Government Inter-Organizational Cooperation of Emergency Management}

Need to establish a stable emergency management professional team, while the inter-departmental emergency drills and regular emergency training. The purpose of emergency management training is to improve the members' emergency management capabilities, and the effect of emergency management training should be able to withstand the test of emergency management practices. To improve the training of emergency management targeted: First, we must thoroughly understand the training objectives of the job; the second is to deeply grasp the training object facing the problem; third is to select the training object for the characteristics of training.

\subsection{Strengthen the Capacity of the Various Departments to Adopt and Co-Decision Making}

Firstly, strengthen the construction of the emergency headquarters of the func- 
tional groups, to enhance the district-level contingency units of the unit level of coordination. According to the requirements of the special emergency headquarters, and the types of emergencies identified in the special emergency plans and their emergency management requirements, planning and design of districtlevel unified government emergency command team functional groups to determine the functional groups should provide emergency response function and objectives, and responsibilities for emergency management of different types of emergencies. On this basis, determine the lead units and support units of each functional group. Secondly, clear the special emergency headquarters functional group construction requirements, establish the information communication between the lead unit and the supporting units of each functional group, the knowledge and resource sharing mechanism, as well as the functional groups of the operating procedures. Finally, strengthen the construction of special emergency headquarters functional group, attention to the functional groups and units involved in the exercise, and enhance the coordination level of each unit in emergency response.

\subsection{Establish the Procedures and Mechanisms for Inter-Organizational Trust and Joint Implementation of Emergency Management}

To enhance the cooperation between the district government and its member units and other units to achieve the depth of integration between different departments. Establish communication and resource sharing mechanism, simplify communication links, reduce cooperation costs, thus, promote communication and cooperation efficiency between district contingency and district units in the emergency management work. Secondly, in the emergency drills, we should pay attention to the participation of units in the district, enhance the level of information sharing between the departments and the district units, increase the mutual trust, try to eliminate or reduce the obstacles between the two cooperation.

\subsection{Expand the Channels of Resource Sharing among Government Departments in Inter-Organizational Cooperation}

To establish the cooperation mechanism among the district emergency committee and its member units and social units. In order to enhance the cooperation between the emergency response committee and the social units in the district, the information record system of the key social units should be established to strengthen the communication and knowledge sharing between the social units and the district emergency committees. Secondly, in order to guide the social units to participate in government-led emergency management work effectively, it should be established emergency resources compensation mechanism, to have the maximum guidance of social emergency rescue forces into emergency response work. Finally, consideration may be given to the incorporation of key social units into the coordinating bodies of emergency management, and clarify 
the responsibilities, procedures and requirements of the parties in the areas of communication, emergency resource sharing and coordination of emergency operations in the face of public safety risks, and enhance the level of cross-organizational cooperation.

\subsection{Establish the Emergency Management Information Disclosure Platform; Improve the Emergency Management Information Disclosure System}

China's emergency information disclosure legislation mainly consists of two major contents: First, the "government information disclosure regulations" as the core of the information disclosure legislation related content; the second is the "emergency response law" as the core of the emergency legislation related content. On this basis, the local government emergency management information disclosure system should be improved. In the way of information disclosure, government departments should establish a communication between the exchange of information, the establishment of emergency management responsibility list, to avoid duplication of tasks between departments, resulting in unnecessary personnel and material waste. It not only can timely and effective reception and feedback of emergency supplies information and emergency response situation, but also through information and resources, comprehensive coordination and inter-organizational cooperation, improve the level of trust between organizations, which is conducive to the timely response to emergencies effective.

\section{Conclusion}

The core content of the local government emergency management system and mechanism construction is to establish the cooperation between the member units of the district contingency committee, between the district emergency committee and the units, between the cross-regional governments, the district government and the higher level government Government-led, sector coordination, social participation in the emergency command and linkage system, so as to integrate the emergency management capabilities of the units to achieve emergency management objectives and mission. China's grass-roots government has initially established emergency management organization system, but the emergency management of cross-organizational cooperation needs to be further improved. This paper analyzes the five dimensions of the local government emergency management inter-organizational cooperation theory, and analyzes the five dimensions of inter-organizational joint development, joint implementation, reduced autonomy, resource sharing and trust level, and puts forward the problems existing in the management of local government emergency management, as well as the corresponding countermeasures, for solving the problems caused by the uneven distribution of cross-organizational cooperation resources and the lack of resources, and thus enhance the local government in the emergency management of information transmission and resource allocation capacity. 


\section{References}

[1] Thomson, A.M., Perry, J.L. and Miller, T.K. (2007) Conceptualizing and Measuring Collaboration. Journal of Public Administration Research and Theory, 19, 23-56. https://doi.org/10.1093/jopart/mum036

[2] Bryson, J.M., Crosby, B.C. and Stone, M.M. (2006) The Design and Implementation of Cross-Sector Collaborations: Propositions from the Literature. Public Administration Review, 66, 44-55.

[3] Chris, A. and Gash, A. (2008) Collaborative Governance in Theory and Practice. Public Administration Research and Theory, 18, 543-571.

[4] Provan, K.G. and Milward, H.B. (2001) Do Networks Really Work? A Framework for Evaluating Public-Sector Organizational Networks. Public Administration Review, 61, 414-423. https://doi.org/10.1111/0033-3352.00045

[5] Kirk, E., Nabatchi, T. and Balogh, S. (2001) An Integrative Framework for Collaborative Governance. Journal of Public Administration Research and Theory, 22, 1 29. https://doi.org/10.1093/jopart/mur011

[6] Koschmann, M.A., Kuhn, T.R. and Pfarrer, M.D. (2012) A Communicative Framework of Value in Cross-Sector Partnerships. Academy of Management Review, 37, 332-354. https://doi.org/10.5465/amr.2010.0314

[7] Zhong, K. (2013) Information and Emergency Decision: An Interpretation Framework. China Administration, 338, 77-83.

[8] Pan, F., Gao, M., Yang, Y. and Wen, D. (2013) Management Control of Cross-Organizational Cooperation: A Theoretical Research Framework. China Accounting Review, 11, 71-85.

[9] Li, H. and Ren, X. (2010) Research on Synergetic Governance in the View of Good Governance. Science and Management, 6, 55-58.

[10] Zhou, Y. (2015) China's Public Service Network Governance Research. Management Observation, 587, 52-69.

[11] Waugh, W.L. and Gregory, S. (2006) Collaboration and Leadership for Effective Emergency Management. Public Administration Review, 66, 131-140.

[12] Comfort, L. (1998) Managing Disaster: Strategies and Policy Perspectives. Duke University Press, Durham, 126-146.

[13] Kapucu, N., Arslan, T. and Demiroz, F. (2010) Collaborative Emergency Management and National Emergency Management Network. Disaster Prevention and Management, 19, 452-468. https://doi.org/10.1108/09653561011070376

[14] Kapucu, N. and Garayev, V. (2011) Collaborative Decision-Making in Emergency and Disaster Management. International Journal of Public Administration, 34, 366375. https://doi.org/10.1080/01900692.2011.561477

[15] Jain, N.K. (2000) Floods in a South Asian Context: Critical Reflections on the International Decade and Local Community Participation in Flood Disaster Reduction. Routledge, London, 225-259.

[16] Bingham-Blomgren, L. and O’Leary, R. (2006) Parallel Play, Not Collaboration: Missing Connections. Public Administration Review, No. 6, 161-167. https://doi.org/10.1111/j.1540-6210.2006.00686.x

[17] Chen, B. and Graddy, E.A. (2005) Inter-Organizational Collaborations for Public Service Delivery: A Frame Work of Preconditions, Processes, and Perceived Outcomes. ARNOVA Conference, Washington DC, 17-19 November 2005.

[18] Thomson, A.M., Perry, J.L. and Miller, T.K. (2008) Forthcoming. Linking Collaboration Processes and Outcomes: Foundations for Advancing Empirical Theory. In: 
O'Leary, R. and Bingham, L., Eds., Collaborative Public Management. The Big Questions, Sharpe, Armonk.

Submit or recommend next manuscript to SCIRP and we will provide best service for you:

Accepting pre-submission inquiries through Email, Facebook, LinkedIn, Twitter, etc. A wide selection of journals (inclusive of 9 subjects, more than 200 journals)

Providing 24-hour high-quality service

User-friendly online submission system

Fair and swift peer-review system

Efficient typesetting and proofreading procedure

Display of the result of downloads and visits, as well as the number of cited articles Maximum dissemination of your research work

Submit your manuscript at: http://papersubmission.scirp.org/

Or contact jss@scirp.org 